\title{
An Increasing Trend in the Prevalence of Polypharmacy in Sweden: A Nationwide Register- Based Study
}

\author{
Naiqi Zhang ${ }^{1}$, Jan Sundquist ${ }^{1,2,3}$, Kristina Sundquist $^{1,2,3}$ and Jianguang $\mathrm{Ji}^{1 *}$ \\ ${ }^{1}$ Center for Primary Health Care Research, Lund University/Region Skåne, Malmö, Sweden, ${ }^{2}$ Department of Family Medicine \\ and Community Health, Department of Population Health Science and Policy, Icahn School of Medicine at Mount Sinai, \\ New York, NY, United States, ${ }^{3}$ Center for Community-Based Healthcare Research and Education (CoHRE), Department of \\ Functional Pathology, School of Medicine, Shimane University, Matsue, Japan
}

OPEN ACCESS

Edited by:

Joseph O. Fadare,

Ekiti State University, Nigeria

Reviewed by: Janet Sultana

University of Messina, Italy

Domenico Criscuolo, Italian Society of Pharmaceutical

Medicine, Italy

*Correspondence: Jianguang $\mathrm{J}$

Jianguang.ji@med.lu.se

Specialty section:

This article was submitted to

Pharmaceutical Medicine and Outcomes Research,

a section of the journal

Frontiers in Pharmacology

Received: 07 January 2020 Accepted: 05 March 2020

Published: 18 March 2020

Citation:

Zhang N, Sundquist J, Sundquist K and Ji J (2020) An Increasing Trend in the Prevalence of Polypharmacy in Sweden: A Nationwide Register-Based Study.

Front. Pharmacol. 11:326. doi: 10.3389/fphar.2020.00326
Aim: Polypharmacy is becoming a global health problem. The aims of this study were to evaluate the temporal trends in the prevalence of polypharmacy in Sweden and to explore polypharmacy disparities by age, gender, education, and immigration status.

Methods: Polypharmacy and excessive polypharmacy were evaluated using data extracted from the Swedish Prescribed Drug Register between 2006 and 2014. Polypharmacy was defined as being exposed to five or more drugs and excessive polypharmacy was defined as being exposed to 10 or more drugs during 1 month respectively. Average annual percent change (AAPC) was calculated using Joinpoint Statistical Software.

Results: The prevalence of polypharmacy increased from $16.9 \%$ in 2006 to $19.0 \%$ in 2014 with an AAPC of 1.3; the prevalence of excess polypharmacy increased from 3.8\% in 2006 to $5.1 \%$ in 2014 with an AAPC of 3.4. The prevalence of polypharmacy and excessive polypharmacy increased dramatically with age and peaked up to $79.6 \%$ and $36.4 \%$ in individuals aged 90 and above respectively. Females and individuals with lower education level were associated with a higher rate of polypharmacy and excessive polypharmacy. Immigrants from Middle-Eastern countries had the highest rate of polypharmacy and excessive polypharmacy, whereas individuals from Western Europe countries had the lowest rate.

Conclusion: The prevalence of polypharmacy has increased gradually in Sweden during the past decade. Individuals with older age, female sex, or lower education have a higher rate of polypharmacy and excessive polypharmacy. Immigrants from Middle-Eastern countries showed a higher rate of polypharmacy.

Keywords: polypharmacy, prevalence, temporal trend, national cohort, Sweden 


\section{INTRODUCTION}

During recent decades, life expectancy for the world's population has increased dramatically, especially for the population in the developed countries (Mathers et al., 2015), when the leading causes of death shifted from infectious and acute diseases to non-communicable and chronic diseases (Collaborators, 2017). Along with population aging, the prevalence of multimorbidity as well as polypharmacy, i.e. individuals using different medications simultaneously, has increased gradually and become a global health problem (Lipska et al., 2016). Individuals with multimorbidity might benefit from concurrent use of different medications to improve the quality of life and longevity. However, multiple medications may lead to the increased risk of adverse drug reactions (Koh et al., 2005) and many unexpected negative effects caused by unknown drug interactions (Bushardt et al., 2008) and unnecessary health expenditure (Hovstadius and Petersson, 2013).

A previous study based on a national representative survey in the United States showed an alarming uptrend of polypharmacy from 1999 to 2012 (Kantor et al., 2015); this was consistent with another regional register-based study from the United Kingdom using data for the period between 1995 and 2010 (Guthrie et al., 2015). It is thus highly necessary to explore whether the uptrend of polypharmacy might be reliable based on data from nationwide registers and from countries with a national social welfare system, which could not be affected by selection and information bias. Previous studies of polypharmacy in Sweden mainly focused on elderly individuals (Johnell and Klarin, 2007; Haider et al., 2009; Wastesson et al., 2016; Morin et al., 2018; Wastesson et al., 2019), and studies included the whole population were outdated (Hovstadius et al., 2009; Hovstadius et al., 2010). Therefore, an updated assessment on the prevalence and temporal trend of multiple medications is highly needed. In addition, it is still largely unknown whether polypharmacy might be associated with common demographic factors, such as gender, education, and immigration status. In this study using Swedish data, we aimed to describe the temporal trend of polypharmacy using the entire Swedish population and to explore the associations of polypharmacy with gender, education, and immigration status.

\section{MATERIALS AND METHODS}

\section{Study Population}

This study was approved by the Ethics Committee at Lund University, Sweden. The study population was the entire Swedish population who was alive on Jan 1st, 2006 or being born and migrated to Sweden between Jan 1st, 2006 and Dec 31st, 2014. We used the Swedish Prescribed Drug Register to evaluate multiple use of medications occurring among the entire Swedish population from 2006 to 2014. This register was created on 1st July 2005 and includes data on all prescribed drugs dispensed at pharmacies in Sweden (Ji et al., 2018; Huang et al., 2019). The rate of missing patient identity data is estimated to be lower than $0.3 \%$ (Wettermark et al., 2007).

In addition, we obtained sociodemographic characteristics, including age, sex, country of birth, and highest education level from Statistics Sweden's Total Population Register and Population Housing Census. The Swedish personal identification number, which is assigned upon birth in Sweden or, for immigrants, when registered in the Swedish population register, was used to link different registers and was then replaced with serial numbers to ensure people's integrity.

\section{Outcome Measurement}

We defined polypharmacy as individuals exposed to five or more drugs during a calendar month, and excessive polypharmacy as individuals exposed to 10 or more drugs in a month (Hovstadius et al., 2009; Wastesson et al., 2019). As shown in Supplementary Figure 1, we calculated each individual's drug exposure during a specific calendar month using the following data: a) the date of drug dispensed; b) the defined daily doses per package; $c$ ) the number of dispensed packages. The duration of each dispensed drug was calculated by the defined daily doses per package multiplied by the number of dispensed packages. The number of different drugs used in each calendar month was retrieved according to seven-digit Anatomical Therapeutic Chemical Classification (ATC) codes.

\section{STATISTICAL ANALYSIS}

To make the data comparable, the rates of polypharmacy and excessive polypharmacy were age-standardized using the Swedish population distribution in 2006 as the standard population. The study population was censored at the end of the study (Dec 31st, 2014), the date of death, or the date of emigration, whichever came first. Stratified results grouped by age ( $<60$ years, $60-69$ years, $70-79$ years, $80-89$ years, $\geq 90$ years), sex, education levels, and country at birth were presented separately. Education level was classified into three groups, 0 to 9 years of schooling (elementary or compulsory education), 10 and 11 years of education (upper secondary education), and 12 years and above (higher education). Country at birth was grouped according to geographic areas: Sweden, Northern European country, Western European country, Eastern European country, Africa, Middle-Eastern country, and others. Prevalence rate ratios (PRRs) along with 95\% confidence intervals (95\% CIs) were calculated by dividing the prevalence rates in the study groups by that of the reference group. 
We calculated the frequencies and ratios using Microsoft Excel (Office $365 \mathrm{MSO}$ version 16.0). To assess the trend of polypharmacy and excessive polypharmacy during 20062014, we used joinpoint regression analysis which fitted a series of connected lines to the prevalence of polypharmacy and excessive polypharmacy. We joined straight-line segments at joinpoints, where the slope of prevalence trend significantly changed. If the trend of polypharmacy was a continuing straight-line without joint point, we presented it as missing. Average annual percent change (AAPC) was calculated as a geometrically weighted average of various annual percent change (APC) values from the regression analysis to describe the temporal trends of polypharmacy and excessive (Kim et al., 2000; Clegg et al., 2009). This analysis was conducted using Joinpoint Statistical Software (version 4.7.0.0).

\section{RESULTS}

Table 1 shows the demographic and clinical characteristics of the study population during the study period from 2006 to 2014. The study population has increased from 9111430 in 2006 to 9747342 in 2017. Swedes accounted for $87.1 \%$ in 2006 , and it was $83.5 \%$ in 2014 . The top 10 drugs used in Sweden were phenoxymethylpenicillin, paracetamol, acetylsalicylic acid, diclofenac, simvastatin, omeprazole, metoprolol, furosemide, doxycycline, mucolytics.

Table 2 shows the prevalence of polypharmacy and excessive polypharmacy from 2006 to 2014 . The rate of polypharmacy was $16.9 \%$ in 2006; it increased to $19.0 \%$ in 2014 with a significant AAPC of 1.3. The rate of excessive polypharmacy for the same period increased from $3.8 \%$ to $5.1 \%$ with a more remarkable AAPC of 3.4.

In 2014, the prevalence of polypharmacy and excessive polypharmacy was 79.6 and $36.4 \%$ respectively in age group 90 and above. Compared with individuals aged $0-59$ years, the PRR of polypharmacy and excessive polypharmacy among individuals aged 90 and above was 11.24 (95\%CI 11.13-11.36) and 31.21 (95\%CI 30.78-31.66), respectively (Table 3). The rate of polypharmacy and excessive polypharmacy in females was continuously higher than males during the study period, and the PRRs (95\% CIs) were 1.20 (95\% CIs 1.20-1.20) and 1.26 (95\% CIs $1.25-1.26$ ), respectively. The rate of polypharmacy and excessive polypharmacy was lowest among individuals with the highest education, and the PRRs (95\% CIs) were $0.77(0.77,0.77)$ for polypharmacy and 0.66 $(0.65,0.66)$ for excessive polypharmacy compared with individuals with the lowest education. Immigrants from Middle-Eastern countries had the highest rates of polypharmacy and excessive polypharmacy, and the PRRs were 1.21 (95\%CI $1.20-1.22)$ and 1.63 (95\%CI 1.61-1.65) respectively compared with native Swedes. Immigrants from Western European countries had the lowest rates; a PRR of
0.80 (95\%CI $0.79-0.81)$ for polypharmacy and 0.83 (95\%CI 0.81-0.85) for excessive polypharmacy (Table 3 ).

Figures 1 and 2 show the temporal trend of polypharmacy and excessive polypharmacy stratified by age group, sex, education level, and birth country respectively. The rate of polypharmacy and excessive polypharmacy increased significantly in all age groups during the study period from 2006 to 2014 (Tables 4 and 5).

\section{DISCUSSION}

In this nationwide register-based study, a comprehensive assessment of the temporal trend in the prevalence of polypharmacy and excessive polypharmacy found that the prevalence increased gradually from 2006 to 2014. The increase was independent of gender, age, education, and immigration status, which suggests that the increased prevalence of the changes concerning polypharmacy might reflect the development of new clinical guidelines, the improved health needs of the general population, as well as the enhanced understanding of the importance of disease prevention. In addition, we found that females, individuals with a lower education, and immigrants from Middle-Eastern countries to Sweden had a higher prevalence of polypharmacy.

It should be noted that the measurement and definition of polypharmacy varied from different studies. However, our finding of an increased prevalence of polypharmacy is consistent with studies from other developed countries (Fincke et al., 2005; Gillette et al., 2015; Masnoon et al., 2017). In the National Health and Nutrition Examination Survey from the United States, the percentage of adults aged 20 and older that had polypharmacy increased remarkably from $8.2 \%$ in $1999-2000$ to $15.0 \%$ in $2011-2012$ and they defined polypharmacy as using five or more prescription drugs 30 days prior to the survey interview (Kantor et al., 2015). A population database analysis from the United Kingdom showed that the proportion of adults that reported polypharmacy (dispensed five or more drugs) almost doubled from $11.2 \%$ in 1995 to $20.8 \%$ in 2010 , and the proportion of excessive polypharmacy (dispensed 10 or more drugs) tripled from 1.7 to $5.8 \%$ (Guthrie et al., 2015) during this same period. A Swedish nationwide study based on data retrieved from the Swedish Prescribed Drug Register reported that the rate of individuals who were prescribed five or more drugs within a 3 -month period increased from 10.2 to $11.1 \%$, and the rate of individuals who were prescribed 10 or more drugs within a 3 -month period increased from 2.1 to $2.4 \%$ (Hovstadius et al., 2010). With the development of medical care, a growing number of chronic diseases can be treated thus resulting in an increasing number of people living with multimorbidity and taking multiple medications at the same time to treat each condition. Besides, the increased application of primary and secondary preventative strategies also improved multiple medication use (Mantel-Teeuwisse et al., 
TABLE 1 | Demographic and clinical characteristics of Swedish population from 2006 to 2014

\begin{tabular}{|c|c|c|c|c|c|c|c|c|c|}
\hline & $2006(n, \%)$ & $2007(n, \%)$ & $2008(n, \%)$ & $2009(n, \%)$ & $2010(n, \%)$ & $2011(n, \%)$ & $2012(n, \%)$ & $2013(n, \%)$ & $2014(n, \%)$ \\
\hline Overall & $9111430(100)$ & $9181434(100)$ & $9255323(100)$ & 9340105 (100) & 9415487 (100) & 9482760 (100) & 9555806 (100) & $9644811(100)$ & $9747342(100)$ \\
\hline \multicolumn{10}{|l|}{ Gender } \\
\hline Male & $4522476(49.6)$ & 4563049 (49.7) & $4603116(49.7)$ & $4648716(49.8)$ & $4690246(49.8)$ & $4726808(49.8)$ & $4765887(49.9)$ & $4814338(49.9)$ & $4872228(50.0)$ \\
\hline Female & $4588954(50.4)$ & $4618385(50.3)$ & 4652207 (50.3) & 4691389 (50.2) & 4725241 (50.2) & $4755952(50.2)$ & $4789919(50.1)$ & $4830473(50.1)$ & $4875113(50.0)$ \\
\hline \multicolumn{10}{|l|}{ Age group } \\
\hline$<60$ & $6925232(76.0)$ & $6950399(75.7)$ & $6980437(75.4)$ & 7023907 (75.2) & $7064110(75.0)$ & 7100679 (74.9) & $7143970(74.8)$ & $7200729(74.7)$ & $7272492(74.6)$ \\
\hline $60-69$ & $1037351(11.4)$ & $1077136(11.7)$ & 1111646 (12.0) & $1139190(12.2)$ & $1161824(12.3)$ & $1175885(12.4)$ & $1179493(12.3)$ & $1175241(12.2)$ & $1161103(11.9)$ \\
\hline $70-79$ & $658603(7.2)$ & $662943(7.2)$ & $670131(7.2)$ & 682627 (7.3) & $692650(7.4)$ & $707978(7.5)$ & $734195(7.7)$ & 771126 (8.0) & $814338(8.4)$ \\
\hline 80-89 & $414648(4.6)$ & $414029(4.5)$ & $415137(4.5)$ & $414400(4.4)$ & $411160(4.4)$ & $408208(4.3)$ & $406916(4.3)$ & $404700(4.2)$ & $404412(4.1)$ \\
\hline $90+$ & $75596(0.8)$ & $76927(0.8)$ & $77972(0.8)$ & $79981(0.9)$ & $85743(0.9)$ & $90010(0.9)$ & $91232(1.0)$ & $93015(1.0)$ & $94996(1.0)$ \\
\hline \multicolumn{10}{|l|}{ Education, year } \\
\hline $0-9$ & 3052708 (33.5) & 3130921 (34.1) & $3215295(34.7)$ & 3307538 (35.4) & 3399741 (36.1) & 3489885 (36.8) & 3596265 (37.6) & 3743101 (38.8) & $3902423(40.0)$ \\
\hline $10-11$ & $3423742(37.6)$ & $3408622(37.1)$ & 3390714 (36.6) & $3372882(36.1)$ & 3350355 (35.6) & 3327298 (35.1) & $3302523(34.6)$ & 3269693 (33.9) & $3237560(33.2)$ \\
\hline $12+$ & $2634980(28.9)$ & 2641891 (28.8) & $2649314(28.6)$ & 2659685 (28.5) & 2665391 (28.3) & 2665577 (28.1) & $2657018(27.8)$ & 2632017 (27.3) & $2607359(26.8)$ \\
\hline \multicolumn{10}{|l|}{ Birth country } \\
\hline Sweden & 7938009 (87.1) & 7955099 (86.6) & $7974718(86.2)$ & $8002682(85.7)$ & 8030609 (85.3) & $8055524(84.9)$ & 8082598 (84.6) & $8111318(84.1)$ & $8143852(83.5)$ \\
\hline Northern European country & $273957(3.0)$ & $272629(3.0)$ & $269670(2.9)$ & $266519(2.9)$ & $263228(2.8)$ & $259748(2.7)$ & $256156(2.7)$ & $252054(2.6)$ & $248484(2.5)$ \\
\hline Western European country & $112866(1.2)$ & $117131(1.3)$ & $122625(1.3)$ & $126691(1.4)$ & $128923(1.4)$ & $132849(1.4)$ & $137052(1.4)$ & $141795(1.5)$ & $145881(1.5)$ \\
\hline Eastern European country & $242979(2.7)$ & $253645(2.8)$ & $263478(2.8)$ & $271210(2.9)$ & $277173(2.9)$ & $282846(3.0)$ & 288457 (3.0) & $294510(3.1)$ & $302459(3.1)$ \\
\hline African country & $59401(0.7)$ & $65032(0.7)$ & $71875(0.8)$ & $82686(0.9)$ & $93283(1.0)$ & $100056(1.1)$ & $108291(1.1)$ & $124477(1.3)$ & $133224(1.4)$ \\
\hline Middle-Eastern country & $219967(2.4)$ & $237768(2.6)$ & $253500(2.7)$ & $267883(2.9)$ & $277860(3.0)$ & $287172(3.0)$ & $298629(3.1)$ & $317343(3.3)$ & $348217(3.6)$ \\
\hline Others & $264251(2.9)$ & $280130(3.1)$ & 299457 (3.2) & 322434 (3.5) & $344411(3.7)$ & $364565(3.8)$ & $384623(4.0)$ & $403314(4.2)$ & $425225(4.4)$ \\
\hline \multicolumn{10}{|l|}{ Comorbidity } \\
\hline Diabetes & 240435 (2.6) & $238353(2.6)$ & $237138(2.6)$ & $236554(2.5)$ & $237334(2.5)$ & $239225(2.5)$ & $240729(2.5)$ & $243127(2.5)$ & $248011(2.5)$ \\
\hline COPD & $171402(1.9)$ & $169890(1.9)$ & $169002(1.8)$ & $168288(1.8)$ & $168037(1.8)$ & $167960(1.8)$ & $168288(1.8)$ & $168611(1.7)$ & $168987(1.7)$ \\
\hline $\mathrm{CH}$ & $150720(1.7)$ & $154533(1.7)$ & $159092(1.7)$ & $163437(1.7)$ & $167926(1.8)$ & $172000(1.8)$ & $172637(1.8)$ & $180219(1.9)$ & $183622(1.9)$ \\
\hline \multicolumn{10}{|l|}{ Prescription drug use } \\
\hline Phenoxymethylpenicillin & $948147(10.4)$ & $991082(10.8)$ & $963254(10.4)$ & 889696 (9.5) & $897428(9.5)$ & $905577(9.5)$ & $886665(9.3)$ & 789808 (8.2) & $788097(8.1)$ \\
\hline Paracetamol & $834350(9.2)$ & $857767(9.3)$ & $898881(9.7)$ & 942925 (10.1) & $975973(10.4)$ & 999436 (10.5) & $1047975(11.0)$ & $1096761(11.4)$ & $1154370(11.8)$ \\
\hline Acetylsalicylic acid & $691013(7.6)$ & $708853(7.7)$ & 724567 (7.8) & $732815(7.8)$ & $731154(7.8)$ & $721288(7.6)$ & $707108(7.4)$ & $682098(7.1)$ & $680786(7.0)$ \\
\hline Diclofenac & $679818(7.5)$ & $640122(7.0)$ & $660245(7.1)$ & $656336(7.0)$ & $653810(6.9)$ & $643328(6.8)$ & $559870(5.9)$ & $446127(4.6)$ & $416384(4.3)$ \\
\hline Simvastatin & $490985(5.4)$ & 553028 (6.0) & 610378 (6.6) & $679019(7.3)$ & $701853(7.5)$ & $701501(7.4)$ & $677366(7.1)$ & $634840(6.6)$ & $632482(6.5)$ \\
\hline Omeprazole & $464277(5.1)$ & $517365(5.6)$ & 569537 (6.2) & $613375(6.6)$ & $654976(7.0)$ & $704698(7.4)$ & $729480(7.6)$ & $734797(7.6)$ & $751624(7.7)$ \\
\hline Metoprolol & $434802(4.8)$ & $464733(5.1)$ & 486946 (5.3) & $502354(5.4)$ & $517579(5.5)$ & $533025(5.6)$ & $545623(5.7)$ & $554950(5.8)$ & $558831(5.7)$ \\
\hline Furosemide & 389979 (4.3) & $379300(4.1)$ & 373847 (4.0) & 363981 (3.9) & $355607(3.8)$ & 345988 (3.6) & 338335 (3.5) & $330374(3.4)$ & 329521 (3.4) \\
\hline Doxycycline & $370012(4.1)$ & 387912 (4.2) & 345999 (3.7) & 299605 (3.2) & 301999 (3.2) & 330838 (3.5) & 310959 (3.3) & $256672(2.7)$ & $248519(2.5)$ \\
\hline Mucolytics & 358851 (3.9) & 366866 (4.0) & 343667 (3.7) & 339617 (3.6) & $405205(4.3)$ & $375345(4.0)$ & 333598 (3.5) & 318780 (3.3) & 324846 (3.3) \\
\hline
\end{tabular}


TABLE 2 | Age-standardized rate of polypharmacy and excessive polypharmacy between 2006 and 2014

\begin{tabular}{|c|c|c|c|c|c|}
\hline & \multirow{2}{*}{$\begin{array}{c}\text { No. of } \\
\text { individuals }\end{array}$} & \multicolumn{2}{|c|}{ Polypharmacy } & \multicolumn{2}{|c|}{ Excessive polypharmacy } \\
\hline & & No. & $\%^{a}$ & No. & $\%^{a}$ \\
\hline 2006 & 9111430 & 1500452 & 16.9 & 333912 & 3.8 \\
\hline 2007 & 9181434 & 1570231 & 17.5 & 356856 & 4.0 \\
\hline 2008 & 9255323 & 1606057 & 17.7 & 371246 & 4.1 \\
\hline 2009 & 9340105 & 1634487 & 17.8 & 380362 & 4.2 \\
\hline 2010 & 9415487 & 1668156 & 18.0 & 386249 & 4.2 \\
\hline 2011 & 9482760 & 1693447 & 18.1 & 390254 & 4.2 \\
\hline 2012 & 9555806 & 1721687 & 18.2 & 397206 & 4.2 \\
\hline 2013 & 9644811 & 1803681 & 18.8 & 440049 & 4.6 \\
\hline \multirow[t]{2}{*}{2014} & 9747342 & 1850219 & 19.0 & 497860 & 5.1 \\
\hline & & AAPC & $95 \% \mathrm{Cl}$ & AAPC & $95 \% \mathrm{Cl}$ \\
\hline $\begin{array}{l}\text { Average Annual } \\
\text { Percent Change } \\
\text { (AAPC) }\end{array}$ & & 1.3 & $(1.0,1.6)$ & 3.4 & $(1.7,5.1)$ \\
\hline
\end{tabular}

${ }^{a}$ Rates were adjusted according to the Swedish population distribution in 2006.

2001; Gorard, 2006). Although many interventions have been implemented to reduce polypharmacy, the results have been unsatisfactory (Kalisch et al., 2011; Tamura et al., 2011; Radcliff et al., 2015; Nguyen and Spinelli, 2016; Antimisiaris and Cutler, 2017).

We found that polypharmacy and excessive polypharmacy is becoming more common not only in older people but also in younger individuals. The prevalence of polypharmacy and excessive polypharmacy increased dramatically with age, peaking up to $79.6 \%$ and $36.4 \%$ in individuals aged 90 and above (Morin et al., 2018). The elderly are more likely to live with multiple chronic conditions thus leading to multiple transitions of health care and polypharmacy. Therefore, the high prevalence of multiple medication use might be associated with the relatively large number of individuals living with multimorbidity rather than due to ageing (Linjakumpu et al., 2002; Hajjar et al., 2007).

Our findings suggested that a higher prevalence of polypharmacy and excessive polypharmacy exists among females, which is consistent with previous studies (Bjerrum et al., 1998; Venturini et al., 2011; Costa et al., 2017; Midao et al., 2018). The possible explanation might be as follows: First, females have a life expectancy advantage over males and they have to live with chronic diseases for a longer period of time (Kontis et al., 2017). Second, females may pay more attention to their health conditions and consequently are more likely to report signs and symptoms to health professionals, which often results in multiple medication use (Santalucia et al., 2015). In addition, women are more likely to participate in preventive health care and are more likely to be prescribed for primary and secondary prevention (Granger et al., 2009).

Individuals with a higher education level were less likely to have polypharmacy and excessive polypharmacy. Some published studies in Sweden reported similar results (Haider et al., 2007; Haider et al., 2009). Furthermore, studies
TABLE 3 | Prevalence rate ratio of polypharmacy and excessive polypharmacy in 2014.

\begin{tabular}{|c|c|c|c|c|c|c|}
\hline & \multicolumn{3}{|c|}{ Polypharmacy } & \multicolumn{3}{|c|}{ Excessive polypharmacy } \\
\hline & Rate $^{a}$ & PRR & $95 \% \mathrm{Cl}$ & Rate $^{a}$ & PRR & $95 \% \mathrm{Cl}$ \\
\hline \multicolumn{7}{|l|}{ Gender } \\
\hline Male & 17.3 & 1 & & 4.5 & 1 & \\
\hline Female & 20.7 & 1.20 & $1.20-1.20$ & 5.7 & 1.26 & $1.25-1.26$ \\
\hline \multicolumn{7}{|l|}{ Age group } \\
\hline$<60$ & 8.5 & 1 & & 1.4 & 1 & \\
\hline 60-69 & 35.9 & 4.52 & $4.50-4.54$ & 9.2 & 6.99 & $6.93-7.05$ \\
\hline $70-79$ & 54.8 & 7.61 & $7.57-7.64$ & 17.0 & 14.32 & $14.20-14.44$ \\
\hline 80-89 & 73.0 & 8.01 & $7.96-8.05$ & 29.0 & 19.32 & 19.14-19.49 \\
\hline $90+$ & 79.6 & 11.24 & $11.13-11.36$ & 36.4 & 31.21 & $30.78-31.66$ \\
\hline \multicolumn{7}{|l|}{ Education, year } \\
\hline $0-9$ & 21.3 & 1 & & 6.2 & 1 & \\
\hline $10-11$ & 19.2 & 0.90 & $0.90-0.90$ & 5.2 & 0.82 & $0.82-0.83$ \\
\hline $12+$ & 16.5 & 0.77 & $0.77-0.77$ & 4.1 & 0.66 & $0.65-0.66$ \\
\hline \multicolumn{7}{|l|}{ Birth country } \\
\hline Sweden & 18.9 & 1 & & 5.0 & 1 & \\
\hline $\begin{array}{l}\text { Northern } \\
\text { European } \\
\text { country }\end{array}$ & 20.1 & 1.06 & $1.05-1.07$ & 6.0 & 1.19 & $1.17-1.21$ \\
\hline $\begin{array}{l}\text { Western } \\
\text { European } \\
\text { country }\end{array}$ & 15.2 & 0.80 & $0.79-0.81$ & 4.1 & 0.83 & $0.81-0.85$ \\
\hline $\begin{array}{l}\text { Eastern } \\
\text { European } \\
\text { country }\end{array}$ & 18.8 & 0.99 & $0.99-1.00$ & 6.0 & 1.21 & $1.19-1.22$ \\
\hline African country & 16.8 & 0.89 & $0.87-0.90$ & 4.5 & 0.90 & $0.87-0.92$ \\
\hline $\begin{array}{l}\text { Middle-Eastern } \\
\text { country }\end{array}$ & 23.0 & 1.21 & $1.20-1.22$ & 8.1 & 1.63 & $1.61-1.65$ \\
\hline Others & 16.8 & 0.89 & $0.88-0.89$ & 5.0 & 1.00 & $0.99-1.01$ \\
\hline
\end{tabular}

${ }^{a}$ Rates were adjusted according to the Swedish population distribution in 2006.

from Malaysia (Ong et al., 2018) and Pakistan (Sarwar et al., 2018) also suggested that older patients with low level education were significantly associated with a higher rate of polypharmacy. The potential explanation might be that patients with a lower level of education are less aware of their basic health needs and expect clinicians to prescribe a greater number of medications (Abdulrahman, 2003). However, it could also be related to a better health in individuals with higher education and a lower need of pharmacological therapy.

We found that the age-standardized rate of polypharmacy and excessive polypharmacy were highest among immigrants from Middle-Eastern countries, and lowest among immigrants from Western European countries. Reports from Israel (Beloosesky et al., 2013) and Turkey (Bahat et al., 2014) observed a relatively high prevalence of polypharmacy, with a rate of $42.6 \%$ among Israelis aged 65 and over and $47.6 \%$ among Turks aged 60 and over, while the rate was much lower in the United Kingdom (8.7\% for age group $60-69,17.1 \%$ for age group $70-79,24.0 \%$ for age group $80+$ ) (Guthrie et al., 2015) and France (Herr et al., 2017) (21.1\% for individuals aged 65 and above).

Polypharmacy is usually associated with numerous negative clinical consequences, especially in the elderly. Previous research 


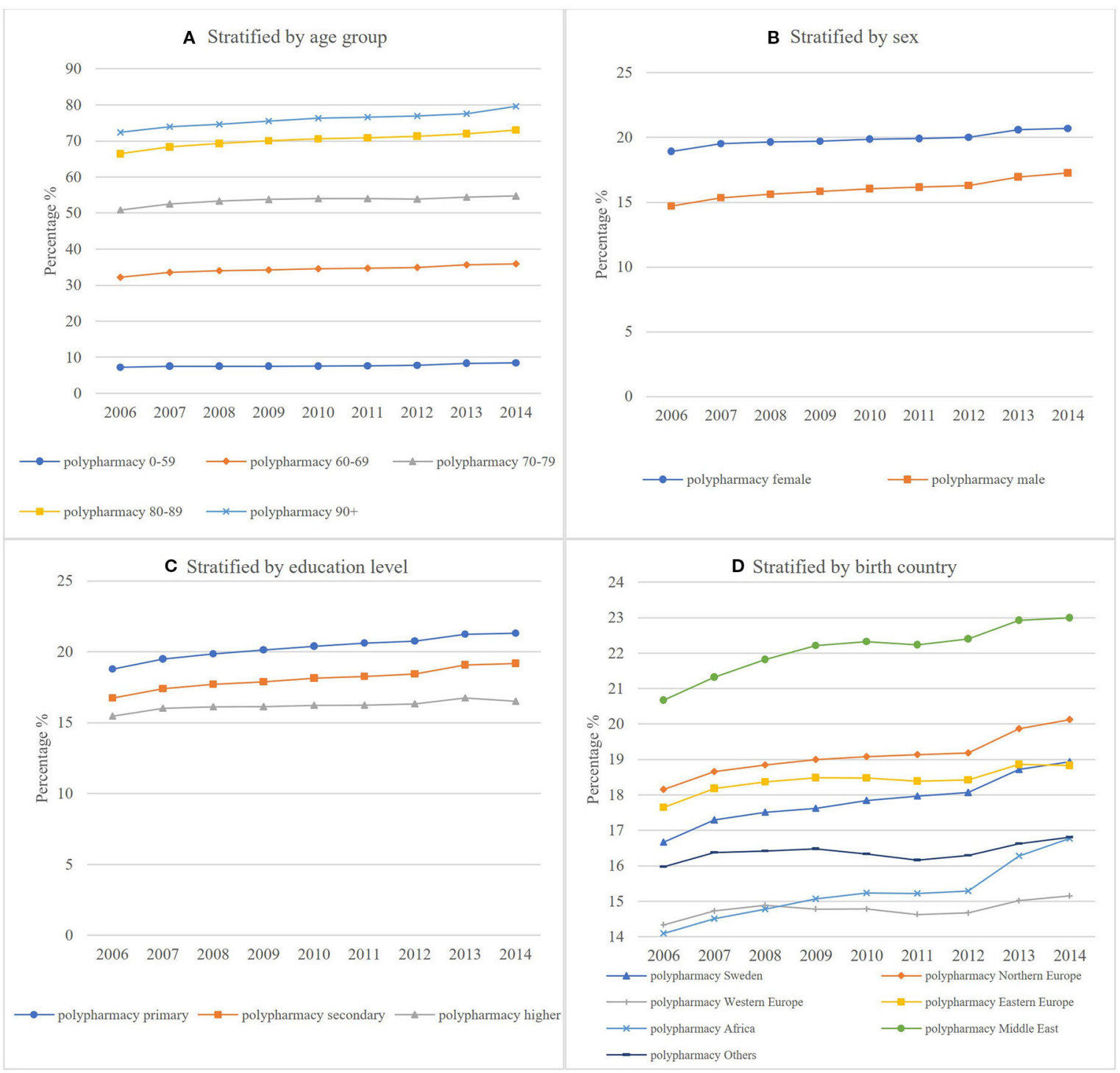

FIGURE 1 | Age-standardized rate of polypharmacy stratified by (A) age group (B) sex (C) education level (D) birth country.

has clearly established that the concurrent use of multiple medications may result in the increasing risk of adverse drug event both in outpatients (Bourgeois et al., 2010) and hospitalized patients (Marcum et al., 2012). Besides, individuals with polypharmacy are predisposed to drug-drug interactions, and the risk increased with the number of medications (Mallet et al., 2007). The rate of non-adherence with drugs (Vik et al., 2004) as well as inappropriate prescribing (Bao et al., 2012) was also associated with polypharmacy, which may lead to consequently subsequent adverse health outcomes such as potential disease progression, treatment failure, and hospitalization. In addition, the unnecessary health expenditure caused by polypharmacy also imposes a huge financial burden on the healthcare system (Hovstadius and Petersson, 2013). Considering the increased risk of health problems caused by polypharmacy, clinicians should balance the benefits and potential harms when prescribing drugs against multimorbidity. The APC of polypharmacy and excessive polypharmacy was higher in 20122014 compared with that in 2006-2011. One possible reason was that following the Syrian Civil War in 2011 many Syrians arrived Sweden as asylum seekers. According to Statistics Sweden, 116,384 citizens of Syria (70,060 men, 46,324 women) were residing in Sweden in 2016. These immigrants from Syria might experience posttraumatic stress disorder and had a higher prevalence of polypharmacy or excessive polypharmacy. However, the joinpoint analysis was data driven may be due to spurious reasons although 


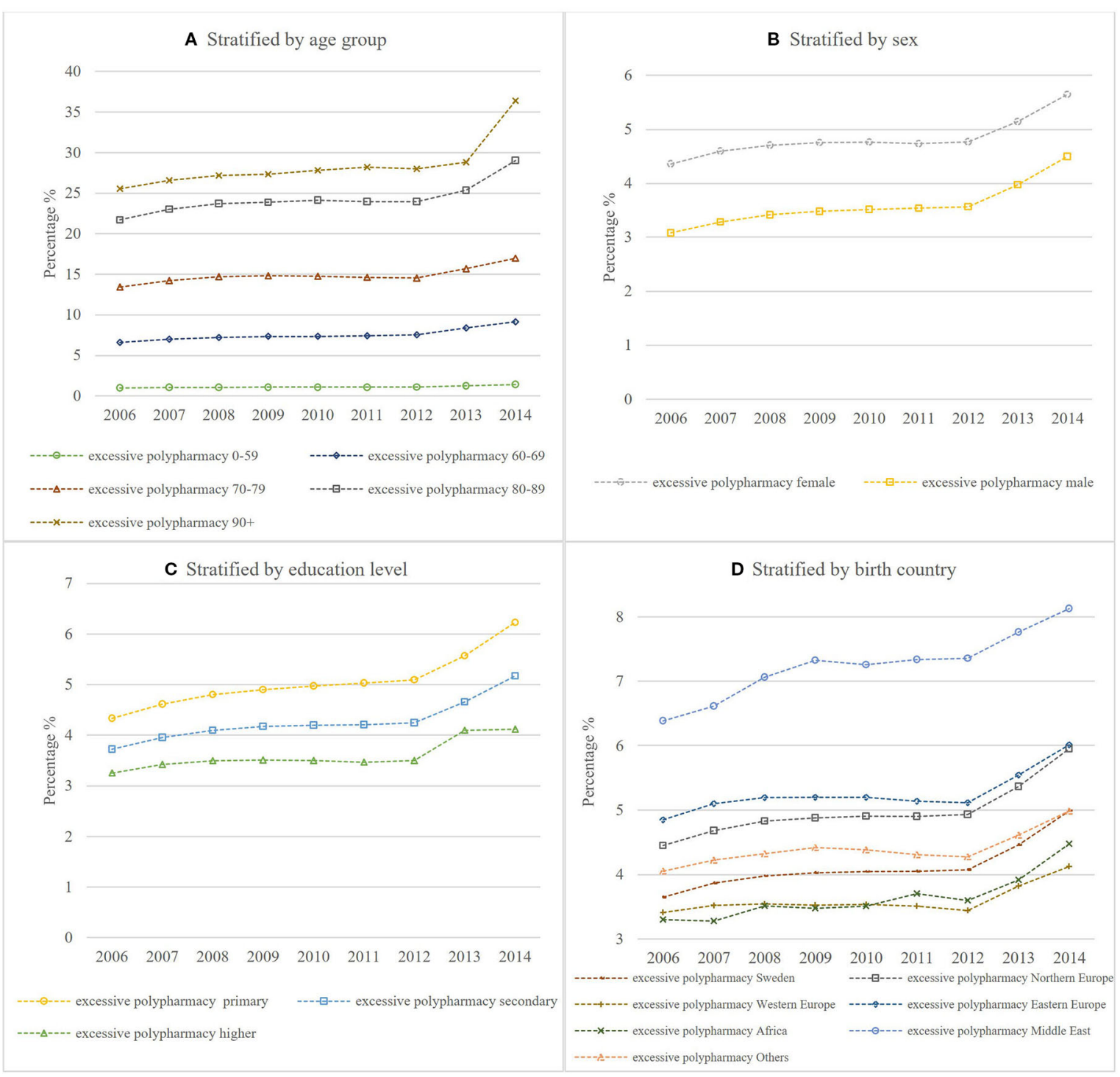

FIGURE 2 | Age-standardized rate of excessive polypharmacy stratified by (A) age group (B) sex (C) education level (D) birth country.

we did our best to identify potential drivers of the change in excessive polypharmacy. We have provided a comprehensive picture of multiple use of prescribed drugs in the entire Swedish population using individual-based exposure of dispensed drugs. The assessments of monthly exposure to polypharmacy provide more accurate information in multiple medication use status than earlier studies only using the data on prescribed date (Johnell and Klarin, 2007; Haider et al., 2009; Hovstadius et al., 2009; Hovstadius et al., 2010). However, there are several limitations that warrant consideration. First, the Swedish Prescribed Drug Register does not include information on over the counter medications and drugs used in hospitals, which may lead to an underestimation of the individual burden of polypharmacy. Besides, we only obtained the information about the drugs being dispensed, but we could not know whether the drugs were actually consumed or the exact date when patients start to take the medications; this may result in misclassification of polypharmacy.

In conclusion, a significant increase of polypharmacy and excessive polypharmacy was found among the Swedish population during the past decade. Individuals with older age, female sex, and lower education may have a higher rate of polypharmacy and excessive polypharmacy. The rates were highest among immigrants from Middle-Eastern countries, and lowest among immigrants from Western European countries. The causes behind this polypharmacy and the sociodemographic disparities need to be further examined. 
TABLE 4 | Results of joinpoint trend analysis for polypharmacy.

\begin{tabular}{|c|c|c|c|c|c|}
\hline & $\begin{array}{l}\text { Average Annual Percent Change } \\
\text { (AAPC) }(95 \% \mathrm{Cl})\end{array}$ & \multicolumn{2}{|r|}{ Trend 1} & \multicolumn{2}{|r|}{ Trend 2} \\
\hline Overall & $1.3(1.0,1.6)$ & - & - & - & - \\
\hline \multicolumn{6}{|l|}{ Gender } \\
\hline Male & $1.8(1.4,2.1)$ & - & - & - & - \\
\hline Female & $1.0(0.7,1.3)$ & - & - & - & - \\
\hline $60-69$ & $1.3(0.9,1.7)$ & 2006-2008 & $2.5(0.5,4.5)$ & 2008-2014 & $0.8(0.5,1.2)$ \\
\hline $70-79$ & $0.9(0.6,1.2)$ & 2006-2008 & $2.5(0.9,4.0)$ & 2008-2014 & $0.3(0.1,0.6)$ \\
\hline 80-89 & $1.1(0.8,1.4)$ & 2006-2008 & $2.1(0.6,3.6)$ & 2008-2014 & $0.8(0.5,1.0)$ \\
\hline $90+$ & $1.0(0.8,1.2)$ & - & - & - & - \\
\hline \multicolumn{6}{|l|}{ Education level, year } \\
\hline $0-9$ & $1.6(1.2,1.9)$ & 2006-2008 & $2.8(1.1,4.6)$ & 2008-2014 & $1.2(0.9,1.5)$ \\
\hline Northern European country & $1.1(0.7,1.4)$ & - & - & - & - \\
\hline Western European country & $0.4(0,0.8)$ & - & - & - & - \\
\hline Eastern European country & $0.6(0.2,0.9)$ & - & - & - & - \\
\hline African country & $2.0(1.2,2.8)$ & 2006-2012 & $1.3(0.6,1.9)$ & 2012-2014 & $4.3(0.3,8.4)$ \\
\hline Middle-Eastern country & $1.3(0.6,1.9)$ & 2006-2008 & $2.8(-0.4,6.1)$ & 2008-2014 & $0.8(0.2,1.3)$ \\
\hline Others & $0.4(0,0.7)$ & - & - & - & - \\
\hline
\end{tabular}

TABLE 5 | Results of joinpoint trend analysis for excessive polypharmacy.

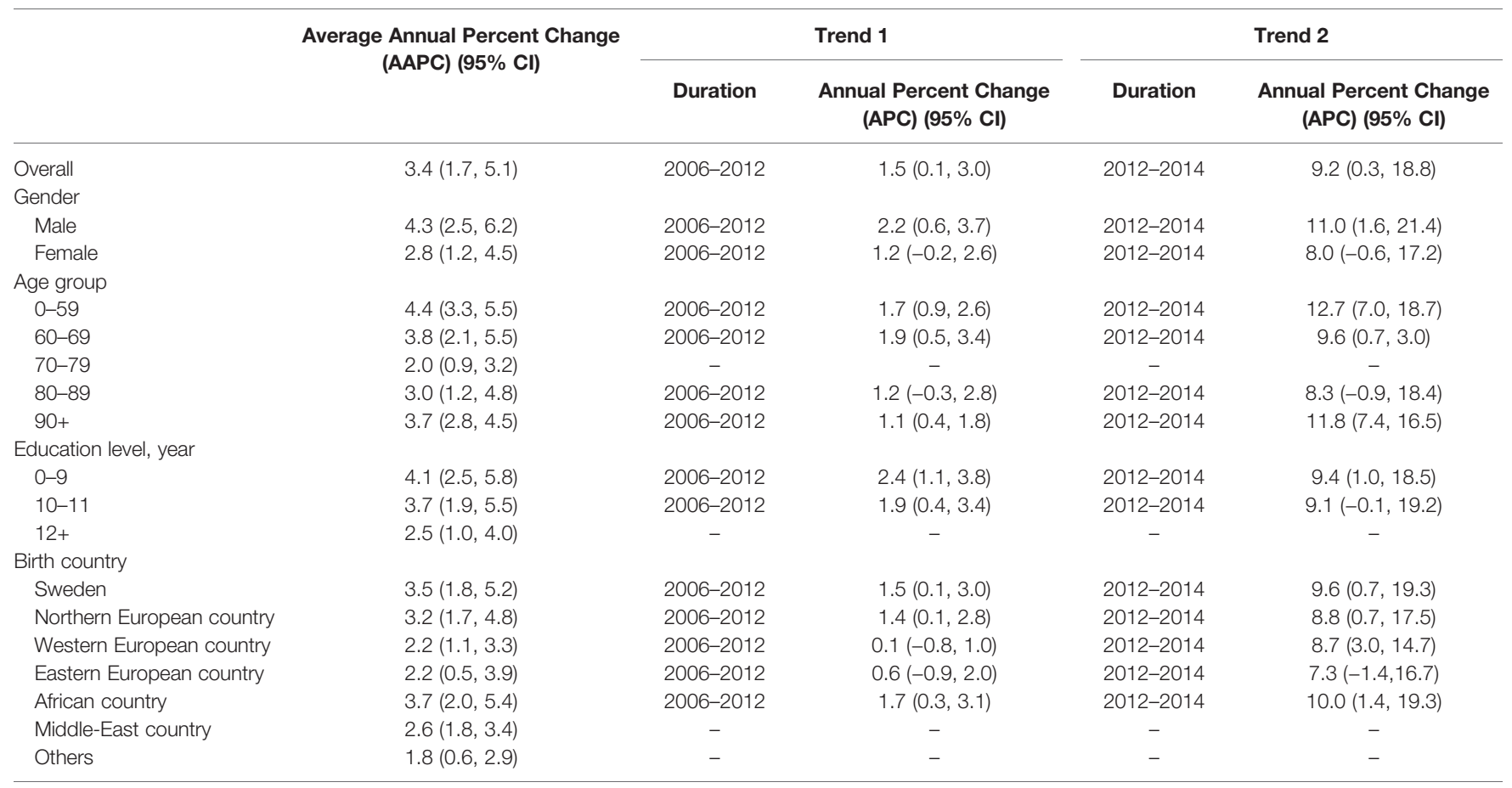

\section{DATA AVAILABILITY STATEMENT}

The datasets generated for this study are available on request to the corresponding author.

\section{ETHICS STATEMENT}

The studies involving human participants were reviewed and approved by the Ethics Committee at Lund University. Written 
informed consent to participate in this study was provided by the participants' legal guardian/next of kin.

\section{AUTHOR CONTRIBUTIONS}

NZ, JS, KS, and JJ were responsible for the study concept and design. JS, KS, and JJ obtained funding. KS and JS acquired the data. NZ did the statistical analysis and drafted the manuscript, and all authors revised it for important intellectual content. The authors confirm that the Principal Investigator for this paper is $\mathrm{JJ}$.

\section{FUNDING}

This work was supported by grants awarded to JJ by the Swedish Research Council (2016-02373), Cancerfonden (CAN2017/340),

\section{REFERENCES}

Abdulrahman, K. A. (2003). What do patient's expect of their general practitioners? J. Family Community Med. 10, 39-45.

Antimisiaris, D., and Cutler, T. (2017a). Managing Polypharmacy in the 15Minute Office Visit. Prim Care 44, 413-428. doi: 10.1016/j.pop.2017.04.003

Bahat, G., Tufan, F., Bahat, Z., Tufan, A., Aydin, Y., Akpinar, T. S., et al. (2014). Comorbidities, polypharmacy, functionality and nutritional status in Turkish community-dwelling female elderly. Aging Clin. Exp. Res. 26, 255-259. doi: 10.1007/s40520-014-0229-8

Bao, Y., Shao, H., Bishop, T. F., Schackman, B. R., and Bruce, M. L. (2012). Inappropriate medication in a national sample of US elderly patients receiving home health care. J. Gen. Intern Med. 27, 304-310. doi: 10.1007/s11606-011-1905-4

Beloosesky, Y., Nenaydenko, O., Nevo, R. F. G., Adunsky, A., and Weiss, A. (2013). Rates, variability, and associated factors of polypharmacy in nursing home patients. Clin. Interventions Aging 8, 1585-1590. doi: 10.2147/CIA.S52698

Bjerrum, L., Sogaard, J., Hallas, J., and Kragstrup, J. (1998). Polypharmacy: Correlations with sex, age and drug regimen - A prescription database study. Eur. J. Clin. Pharmacol. 54, 197-202. doi: 10.1007/s002280050445

Bourgeois, F. T., Shannon, M. W., Valim, C., and Mandl, K. D. (2010). Adverse drug events in the outpatient setting: an 11-year national analysis. Pharmacoepidemiol. Drug Saf. 19, 901-910. doi: 10.1002/pds.1984

Bushardt, R. L., Massey, E. B., Simpson, T. W., Ariail, J. C., and Simpson, K. N. (2008). Polypharmacy: misleading, but manageable. Clin. Interv. Aging 3, 383389. doi: $10.2147 /$ CIA.S2468

Clegg, L. X., Hankey, B. F., Tiwari, R., Feuer, E. J., and Edwards, B. K. (2009). Estimating average annual per cent change in trend analysis. Stat. Med. 28, 3670-3682. doi: 10.1002/sim.3733

Collaborators, G.B.D.C.O.D. (2017). Global, regional, and national age-sex specific mortality for 264 causes of death 1980-2016: a systematic analysis for the Global Burden of Disease Study 2016. Lancet 390, 1151-1210. doi: 10.1016/ S0140-6736(17)32152-9

Costa, J. D., Ceccato, M. D. B., Melo, A. P. S., Acurcio, F. D., and Guimaraes, M. D. C. (2017). Gender differences and psychotropic polypharmacy in psychiatric patients in Brazil: a cross-sectional analysis of the PESSOAS Project. Cadernos Saude Publica 33. doi: 10.1590/0102-311x00168915

Fincke, B. G., Snyder, K., Cantillon, C., Gaehde, S., Standring, P., Fiore, L., et al. (2005). Three complementary definitions of polypharmacy: methods, application and comparison of findings in a large prescription database. Pharmacoepidemiol. Drug Saf. 14, 121-128. doi: 10.1002/pds.966

Gillette, C., Prunty, L., Wolcott, J., and Broedel-Zaugg, K. (2015). A new lexicon for polypharmacy: Implications for research, practice, and education. Res. Soc. Administrative Pharm. 11, 468-471. doi: 10.1016/j.sapharm.2014.08.010 and Crafoordska stiftelsen, to KS by the Swedish Research Council, and to JS by the Swedish Research Council as well as by ALF funding from Region Skåne awarded to JS, KS, and JJ.

\section{ACKNOWLEDGMENTS}

The authors wish to thank the Center for Primary Health Care Research's science editor Patrick Reilly for his valuable comments on the text.

\section{SUPPLEMENTARY MATERIAL}

The Supplementary Material for this article can be found online at: https://www.frontiersin.org/articles/10.3389/fphar.2020.00326/ full\#supplementary-material

Gorard, D. A. (2006). Escalating polypharmacy. QJM 99, 797-800. doi: 10.1093/ qjmed/hcl109

Granger, B. B., Ekman, I., Granger, C. B., Ostergren, J., Olofsson, B., Michelson, E., et al. (2009). Adherence to medication according to sex and age in the CHARM programme. Eur. J. Heart Fail. 11, 1092-1098. doi: 10.1093/eurjhf/hfp142

Guthrie, B., Makubate, B., Hernandez-Santiago, V., and Dreischulte, T. (2015). The rising tide of polypharmacy and drug-drug interactions: population database analysis 1995-2010. BMC Med. 13, 74. doi: 10.1186/s12916-015-0322-7

Haider, S. I., Johnell, K., Thorslund, M., and Fastbom, J. (2007). Trends in polypharmacy and potential drug-drug interactions across educational groups in elderly patients in Sweden for the period 1992-2002. Int. J. Clin. Pharmacol. Ther. 45, 643-653. doi: 10.5414/CPP45643

Haider, S. I., Johnell, K., Weitoft, G. R., Thorslund, M., and Fastbom, J. (2009). The influence of educational level on polypharmacy and inappropriate drug use: a register-based study of more than 600,000 older people. J. Am. Geriatr. Soc. 57, 62-69. doi: 10.1111/j.1532-5415.2008.02040.x

Hajjar, E. R., Cafiero, A. C., and Hanlon, J. T. (2007). Polypharmacy in elderly patients. Am. J. Geriatr. Pharmacother. 5, 345-351. doi: 10.1016/j.amjopharm.2007.12.002

Herr, M., Grondin, H., Sanchez, S., Armaingaud, D., Blochet, C., Vial, A., et al. (2017). Polypharmacy and potentially inappropriate medications: a crosssectional analysis among 451 nursing homes in France. Eur. J. Clin. Pharmacol. 73, 601-608. doi: 10.1007/s00228-016-2193-Z

Hovstadius, B., and Petersson, G. (2013). The impact of increasing polypharmacy on prescribed drug expenditure-a register-based study in Sweden 2005-2009. Health Policy 109, 166-174. doi: 10.1016/j.healthpol.2012.09.005

Hovstadius, B., Astrand, B., and Petersson, G. (2009). Dispensed drugs and multiple medications in the Swedish population: an individual-based register study. BMC Clin. Pharmacol. 9, 11. doi: 10.1186/1472-6904-9-11

Hovstadius, B., Hovstadius, K., Astrand, B., and Petersson, G. (2010). Increasing polypharmacy - an individual-based study of the Swedish population 20052008. BMC Clin. Pharmacol. 10, 16. doi: 10.1186/1472-6904-10-16

Huang, W., Sundquist, J., Sundquist, K., and Ji, J. (2019). Use of Phosphodiesterase 5 Inhibitors Is Associated With Lower Risk of Colorectal Cancer in Men With Benign Colorectal Neoplasms. Gastroenterology 157, 672-681 e674. doi: 10.1053/j.gastro.2019.05.012

Ji, J., Sundquist, J., and Sundquist, K. (2018). Cholera Vaccine Use Is Associated With a Reduced Risk of Death in Patients With Colorectal Cancer: A Population-Based Study. Gastroenterology 154, 86-92 e81. doi: 10.1053/j.gastro.2017.09.009

Johnell, K., and Klarin, I. (2007). The relationship between number of drugs and potential drug-drug interactions in the elderly: a study of over 600,000 elderly patients from the Swedish Prescribed Drug Register. Drug Saf. 30, 911-918. doi: 10.2165/00002018-200730100-00009 
Kalisch, L. M., Caughey, G. E., Roughead, E. E., and Gilbert, A. L. (2011). The prescribing cascade. Aust. Prescriber 34, 162-166. doi: 10.18773/austprescr.2011.084

Kantor, E. D., Rehm, C. D., Haas, J. S., Chan, A. T., and Giovannucci, E. L. (2015). Trends in Prescription Drug Use Among Adults in the United States From 1999-2012. JAMA 314, 1818-1831. doi: 10.1001/jama.2015.13766

Kim, H. J., Fay, M. P., Feuer, E. J., and Midthune, D. N. (2000). Permutation tests for joinpoint regression with applications to cancer rates. Stat Med. 19, 335-351. doi: 10.1002/(SICI)1097-0258(20000215)19:3<335::AID-SIM336>3.0.CO;2-Z

Koh, Y., Kutty, F. B., and Li, S. C. (2005). Drug-related problems in hospitalized patients on polypharmacy: the influence of age and gender. Ther. Clin. Risk Manag 1, 39-48. doi: 10.2147/tcrm.1.1.39.53597

Kontis, V., Bennett, J. E., Mathers, C. D., Li, G., Foreman, K., and Ezzati, M. (2017). Future life expectancy in 35 industrialised countries: projections with a Bayesian model ensemble. Lancet 389, 1323-1335. doi: 10.1016/S0140-6736 (16)32381-9

Linjakumpu, T., Hartikainen, S., Klaukka, T., Veijola, J., Kivela, S. L., and Isoaho, R. (2002). Use of medications and polypharmacy are increasing among the elderly. J. Clin. Epidemiol. 55, 809-817. doi: 10.1016/S0895-4356(02)00411-0

Lipska, K. J., Krumholz, H., Soones, T., and Lee, S. J. (2016). Polypharmacy in the Aging Patient: A Review of Glycemic Control in Older Adults With Type 2 Diabetes. JAMA 315, 1034-1045. doi: 10.1001/jama.2016.0299

Mallet, L., Spinewine, A., and Huang, A. (2007). The challenge of managing drug interactions in elderly people. Lancet $370,185-191$. doi: 10.1016/S0140-6736 (07)61092-7

Mantel-Teeuwisse, A. K., Klungel, O. H., Verschuren, W. M. M., Porsius, A., and De Boer, A. (2001). Comparison of different methods to estimate prevalence of drug use by using pharmacy records. J. Clin. Epidemiol. 54, 1181-1186. doi: 10.1016/S0895-4356(01)00396-1

Marcum, Z. A., Amuan, M. E., Hanlon, J. T., Aspinall, S. L., Handler, S. M., Ruby, C. M., et al. (2012). Prevalence of Unplanned Hospitalizations Caused by Adverse Drug Reactions in Older Veterans. J. Am. Geriatrics Soc. 60, 34-41. doi: 10.1111/j.15325415.2011.03772.x

Masnoon, N., Shakib, S., Kalisch-Ellett, L., and Caughey, G. E. (2017). What is polypharmacy? A systematic review of definitions. BMC Geriatr. 17, 230. doi: 10.1186/s12877-017-0621-2

Mathers, C. D., Stevens, G. A., Boerma, T., White, R. A., and Tobias, M. I. (2015). Causes of international increases in older age life expectancy. Lancet 385, 540548. doi: 10.1016/S0140-6736(14)60569-9

Midao, L., Giardini, A., Menditto, E., Kardas, P., and Costa, E. (2018). Polypharmacy prevalence among older adults based on the survey of health, ageing and retirement in Europe. Arch. Gerontology Geriatrics 78, 213-220. doi: 10.1016/j.archger.2018.06.018

Morin, L., Johnell, K., Laroche, M. L., Fastbom, J., and Wastesson, J. W. (2018). The epidemiology of polypharmacy in older adults: register-based prospective cohort study. Clin. Epidemiol. 10, 289-298. doi: 10.2147/CLEP.S153458

Nguyen, P. V. Q., and Spinelli, C. (2016). Prescribing cascade in an elderly woman. Can. Pharm. J. 149, 122-124. doi: 10.1177/1715163516640811
Ong, S. M., Lim, Y. M. F., Sivasampu, S., and Khoo, E. M. (2018). Variation of polypharmacy in older primary care attenders occurs at prescriber level. BMC Geriatrics 18, 59. doi: 10.1186/s12877-018-0750-2

Radcliff, S., Yue, J. R., Rocco, G., Aiello, S. E., Ickowicz, E., Hurd, Z., et al. (2015). American Geriatrics Society 2015 Updated Beers Criteria for Potentially Inappropriate Medication Use in Older Adults. J. Am. Geriatrics Soc. 63, 2227-2246. doi: 10.1111/jgs.13702

Santalucia, P., Franchi, C., Djade, C. D., Tettamanti, M., Pasina, L., Corrao, S., et al. (2015). Gender difference in drug use in hospitalized elderly patients. Eur. J. Internal Med. 26, 483-490. doi: 10.1016/j.ejim.2015.07.006

Sarwar, M. R., Iftikhar, S., and Sarfraz, M. (2018). Influence of Education Level of Older Patients on Polypharmacy, Potentially Inappropriate Medications Listed in Beer's Criteria, and Unplanned Hospitalization: A Cross-Sectional Study in Lahore, Pakistan. Medicina-Lithuania 54, 57. doi: 10.3390/medicina54040057

Tamura, B. K., Bell, C. L., Lubimir, K., Iwasaki, W. N., Ziegler, L. A., and Masaki, K. H. (2011). Physician intervention for medication reduction in a nursing home: the polypharmacy outcomes project. J. Am. Med. Dir Assoc. 12, 326-330. doi: 10.1016/ j.jamda.2010.08.013

Venturini, C. D., Engroff, P., Ely, L. S., Zago, L. F. D. A., Schroeter, G., Gomes, I., et al. (2011). Gender differences, polypharmacy, and potential pharmacological interactions in the elderly. Clinics 66, 1867-1872. doi: 10.1590/s180759322011001100004

Vik, S. A., Maxwell, C. J., and Hogan, D. B. (2004). Measurement, correlates, and health outcomes of medication adherence among seniors. Ann. Pharmacother. 38, 303-312. doi: 10.1345/aph.1D252

Wastesson, J. W., Canudas-Romo, V., Lindahl-Jacobsen, R., and Johnell, K. (2016). Remaining Life Expectancy With and Without Polypharmacy: A RegisterBased Study of Swedes Aged 65 Years and Older. J. Am. Med. Dir Assoc. 17, 3135. doi: 10.1016/j.jamda.2015.07.015

Wastesson, J. W., Morin, L., Laroche, M. L., and Johnell, K. (2019). How Chronic Is Polypharmacy in Old Age? A Longitudinal Nationwide Cohort Study. J. Am. Geriatr. Soc. 67, 455-462. doi: 10.1111/jgs.15717

Wettermark, B., Hammar, N., Fored, C. M., Leimanis, A., Otterblad Olausson, P. Bergman, U., et al. (2007). The new Swedish Prescribed Drug Registeropportunities for pharmacoepidemiological research and experience from the first six months. Pharmacoepidemiol. Drug Saf. 16, 726-735. doi: 10.1002/pds.1294

Conflict of Interest: The authors declare that the research was conducted in the absence of any commercial or financial relationships that could be construed as a potential conflict of interest.

Copyright (c) 2020 Zhang, Sundquist, Sundquist and Ji. This is an open-access article distributed under the terms of the Creative Commons Attribution License (CC BY). The use, distribution or reproduction in other forums is permitted, provided the original author(s) and the copyright owner(s) are credited and that the original publication in this journal is cited, in accordance with accepted academic practice. No use, distribution or reproduction is permitted which does not comply with these terms. 